\title{
El citocromo P-450 y la respuesta terapéutica a los antimaláricos
}

\author{
Valentina Guzmán ${ }^{1}$ y Jaime Carmona-Fonseca ${ }^{1}$
}

Forma de citar

Guzmán V, Carmona-Fonseca J. El citocromo P-450 y la respuesta terapéutica a los antimaláricos. Rev Panam Salud Publica. 2006;19(1):9-22.

RESUMEN Objetivos. Evaluar la relación entre los factores genéticos y fenotípicos del sistema enzimático del citocromo P-450 y la respuesta terapéutica antimalárica a la cloroquina, la amodiaquina, la mefloquina y el proguanil, así como determinar la influencia de algunos factores biológicos y sociales del hospedero en el comportamiento de este complejo enzimático.

Métodos. Revisión sistemática de las bases de literatura biomédica PubMed, Excerpta Medica, LILACS y SciELO mediante descriptores en español e inglés. Se usaron los siguientes descriptores: "CYP-450" y "citocromo P-450" y sus combinaciones con "proguanil" (y lo mismo con "mefloquina", "cloroquina" $y$ "amodiaquina"), "farmacocinética de proguanil" (y lo mismo con "mefloquina", "cloroquina" y "amodiaquina"), "resistencia a proguanil" (y lo mismo con "mefloquina", "cloroquina" y "amodiaquina"), "metabolismo", "farmacogenética", "enfermedad", "inflamación", "infección", "enfermedad hepática", "malaria", "nutrición" y "desnutrición". Estos mismos términos se usaron en inglés. La búsqueda se limitó a los artículos publicados en español, inglés y portugués hasta el 30 de junio de 2005 y a cuatro medicamentos antimaláricos: amodiaquina, cloroquina, mefloquina y proguanil.

Resultados. Algunos factores genéticos del citocromo P-450 humano (principalmente su polimorfismo), así como otros de tipo biológico y social (la propia presencia de enfermedad, inflamación o infección, la administración de medicamentos antimaláricos y su combinación, y el estado nutricional del paciente), influyen en la actividad de ese complejo enzimático. Solo en la última década se ha abordado el estudio de las bases genéticas de los citocromos y se han podido dilucidar los mecanismos de algunas interacciones entre fármacos y del metabolismo de estos, lo que ha permitido caracterizar el proceso de biotransformación de la amodiaquina y de la cloroquina. Se espera que nuevas investigaciones permitan responder a las interrogantes que aún subsisten, entre ellas cuál es la ruta metabólica de otros medicamentos antimaláricos, la distribución en la población de los alelos de las enzimas que participan en su metabolismo, y la contribución de tales mutaciones al fracaso terapéutico, y predecir la respuesta a los tratamientos antimaláricos.

Conclusiones. La respuesta terapéutica a los medicamentos antimaláricos es un proceso multifactorial y poco comprendido, por lo que no es posible asignar a un fenotipo o a un genotipo una determinada responsabilidad en la respuesta terapéutica antimalárica. Se debe contemplar la influencia de factores biológicos y sociales, tales como la alimentación, el estado nutricional y cualquier proceso inflamatorio e infeccioso concomitante, que puedan ser frecuentes en las zonas con malaria endémica.

Palabras clave Sistema enzimático del citocromo P-450, Plasmodium falciparum, malaria, antimaláricos.

1 Grupo Malaria, Universidad de Antioquia, Medellín, Colombia. La correspondencia debe dirigirse a Valentina Guzmán, Calle 62 No. 52-59, Laboratorio 610, Medellín, Colombia. Correo electrónico: valen@pijaos.udea.edu.co
La respuesta terapéutica a los medicamentos antimaláricos es un proceso poco comprendido y que se ve determinado por muchos factores. Esta res- puesta se evalúa por lo general in vivo tras el tratamiento de personas con malaria (parasitemia asexual y presencia de síntomas) con uno o varios medica- 
mentos antimaláricos - habitualmente por la vía oral- durante un tiempo predeterminado mediante un seguimiento de 14-28 días con evaluaciones clínicas y parasitológicas (1). Los resultados de los estudios in vivo se expresan en términos de una respuesta terapéutica adecuada (exitosa) o de fracaso terapéutico.

La respuesta a los antimaláricos también se puede estudiar in vitro, en un ambiente artificial creado en el laboratorio. En este caso se evalúa si los parásitos que crecen en eritrocitos mantenidos en cultivo son susceptibles (mueren) o resistentes (sobreviven) a la acción de un medicamento dado. Un parásito es resistente a un medicamento si logra sobrevivir o multiplicarse in vitro en presencia de concentraciones que suelen ser suficientes para inhibir su crecimiento. Los resultados de esta evaluación se expresan en términos de la sensibilidad o resistencia del parásito al medicamento. No obstante, esta prueba solo refleja la reacción parasitaria al medicamento sin tomar en cuenta el efecto de la respuesta inmunitaria y de las condiciones fisiológicas y de salud del hospedero.

El fracaso terapéutico y la resistencia a los medicamentos se han convertido en importantes problemas que impiden el control adecuado de la malaria en varios países con malaria endémica (2-4). Hasta el momento no se han estudiado con profundidad los factores del hospedero que pueden afectar a la respuesta terapéutica y casi todas las investigaciones se han centrado en la resistencia de Plasmodium a los medicamentos, en particular la de $P$. falciparum. Los resultados de las evaluaciones in vivo e in vitro no siempre coinciden (5), lo que indica que algunos factores - como la calidad del medicamento, su dosis y vía de administración, los procesos farmacocinéticos, la respuesta inmunitaria del hospedero y su estado nutricional y de salud- pueden desempeñar un papel muy importante.

Hay un gran interés en identificar un "perfil de falla" al tratamiento antimalárico, es decir, un conjunto de características comunes en los pacientes que no responden al tratamiento.
Según estudios realizados en las Islas Salomón, Tailandia y Nigeria, ser niño es un factor pronóstico en relación con el fracaso terapéutico (aunque varía el límite de edad); la desnutrición es otro factor, según algunos estudios en los que se empleó cloroquina (CQ) en el tratamiento; la anemia y la parasitemia elevada se encontraron asociadas con el fracaso terapéutico en un estudio con CQ y en otro con amodiaquina $(\mathrm{AQ})$, aunque los niveles de parasitemia variaron entre 1000 y más de 100000 parásitos/ $\mu \mathrm{L}$ (6-10). No se encontró ninguna asociación entre el fracaso del tratamiento con CQ y la gametocitemia (11), el sexo, la edad, el estado nutricional y el nivel de parasitemia o endemia del lugar $(4,12)$.

Uno de los elementos que determinan la respuesta terapéutica antimalárica es la ruta metabólica de biotransformación del medicamento en el organismo, que puede generar compuestos más activos que el fármaco original $\mathrm{u}$ otros con poca o ninguna actividad o de más rápida excreción. La mayor parte de la biotransformación de muchos medicamentos antimaláricos ocurre en el hígado con la participación del complejo enzimático del citocromo P-450 (CYP-450), también llamado sistema de oxidasas de función mixta o sistema de oxidasas microsomales. Variaciones en la actividad de una o de varias de las enzimas de este complejo pueden hacer que el medicamento no pase a su forma activa o que su conversión sea tan rápida que conduzca a su rápida excreción (13). Varios factores pueden inhibir o inducir la actividad del CYP-450, entre ellos el polimorfismo genético, la desnutrición, la deficiencia de micronutrientes, los procesos infecciosos e inflamatorios y el consumo simultáneo de otros medicamentos metabolizados por la misma vía.

\section{Definición y nomenclatura del CYP-450}

El complejo enzimático del CYP-450 consta de 144 enzimas distribuidas en diversos tejidos y órganos, especial- mente en las membranas del retículo endoplásmico liso del hígado. Estas enzimas participan en la desintoxicación de elementos xenobióticos, como los medicamentos, y en el metabolismo de algunos endobióticos, como los esteroides, los eicosanoides y las vitaminas liposolubles (14).

Cada enzima está compuesta por cuatro elementos: a) un grupo proteínico hémico del tipo de la ferroprotoporfirina IX, en el que el átomo de hierro se encuentra en estado férrico $\left(\mathrm{Fe}^{3+}\right)$; b) una cadena polipeptídica codificada por un solo gen, cuyas variaciones originan las diferencias entre una enzima y otra; c) una enzima flavoproteínica dependiente de NADH; y d) el citocromo b5, relacionado con el transporte del segundo electrón en el proceso oxidativo catalizado por este sistema enzimático (14).

La nomenclatura de las enzimas depende de la familia, la subfamilia y el gen que las codifica. La familia es un grupo de enzimas con una homología estructural de 35 a $40 \%$ y se representa por un número arábigo precedido de la sigla CYP (que identifica al CYP-450), por ejemplo, CYP1, CYP3, etc. Las subfamilias - formadas por enzimas con una homología de 65 a $70 \%$ - se identifican mediante la adición de una letra mayúscula, por ejemplo, CYP3A, CYP2C. La subfamilia CYP3A es la más abundante en los humanos y desempeña un papel importante en el metabolismo de prácticamente la mitad de los medicamentos (14). El gen que codifica una enzima se identifica añadiendo un número arábigo y empleando letra cursiva, por ejemplo CYP2C8, CYP2D6 o CYP3A4 (15).

Las enzimas de este complejo funcionan mediante una serie de reacciones metabólicas en las que se transfieren dos electrones y se incorpora un átomo de oxígeno. Esto lleva a la oxidación del compuesto, la cual aumenta su polaridad, su capacidad de excreción y su solubilidad en agua. Como resultado de este proceso, los precursores (profármacos) se convierten en metabolitos que pueden tener una mayor actividad farmacológica (16). 


\section{Los antimaláricos metabolizados por el CYP-450}

Varias enzimas del complejo del CYP-450 participan en la biotransformación de los medicamentos antimaláricos en el organismo humano (17). Además de participar en el metabolismo de la $C Q$, la $A Q$, la mefloquina $(\mathrm{MQ})$ y el proguanil (PG), estas enzimas también metabolizan la primaquina (la CYP1A2 y la CYP2D6), el artesunato (la CYP2A6) y la halofantrina (la CYP3A4) (18). Aunque en la transformación de la pirimetamina participan también en menor medida las enzimas CYP1B1 y CYP2C19, este sistema de oxidación microsómico no interviene en el procesamiento de la sulfadoxina. La combinación de la pirimetamina y la sulfa- doxina se utiliza muy frecuentemente como tratamiento antimalárico.

En los cuadros 1 y 2 se presentan algunas características de los medicamentos estudiados y de su metabolismo en personas sin malaria. La AQ y la CQ son 4-aminoquinolinas que se usan desde hace 50 años o más como esquizonticidas (eliminan las formas asexuales del parásito que circulan en

CUADRO 1. Características químicas y farmacológicas de cuatro medicamentos antimaláricos metabolizados por el citocromo P-450 ${ }^{a}$

\begin{tabular}{lllll}
\hline \multicolumn{1}{c}{ Características } & \multicolumn{1}{c}{ Cloroquina } & \multicolumn{1}{c}{ Amodiaquina } & Mefloquina & Proguanil \\
\hline Definición química & 4-aminoquinolina (17) & 4-aminoquinolina (17) & Arilamino-alcohol (17) & Biguanida (17) \\
Forma activa & Desetilcloroquina (17) & $\begin{array}{l}\text { Amodiaquina (21) } \\
\text { y desetilamodiaquina }\end{array}$ & Mefloquina (23) & Proguanil (24) y cicloguanil \\
Disponibilidad oral (\%) & $80-90(17)$ & $80-90(17)$ & $85(17)$ & No calculada (17) \\
Unión a proteínas (\%) & $50-60(19)$ & $>90(22)$ & $98(17)$ & $75(25)$ \\
Enzima implicada & $\begin{array}{l}\text { CYP2C8, CYP3A4 y } \\
\text { CYP2D6 (20) }\end{array}$ & CYP2C8 (21) & CYP3A4 (23) & CYP2C19 y CYP2A4 (24) \\
\hline
\end{tabular}

${ }^{a}$ Las fuentes bibliográficas aparecen entre paréntesis.

CUADRO 2. Características del metabolismo de cuatro medicamentos antimaláricos en el que interviene el citocromo P-450ª

\begin{tabular}{|c|c|c|c|c|}
\hline Variable & Cloroquina & Amodiaquina & Mefloquina & Proguanil \\
\hline Dosis mg/kg/día & $25^{\mathrm{b}}(26)$ & $10^{c}(26)$ & 15-25 dosis única (26) & $\ldots$ \\
\hline $\begin{array}{l}\text { Enzima del metabolismo } \\
\text { hepático }\end{array}$ & $\begin{array}{l}\text { CYP2C8, CYP3A4 } \\
\text { y CYP2D6 (20) }\end{array}$ & CYP2C8 (21) & CYP3A4 (29) & CYP2C19, CYP2A4 (24) \\
\hline Metabolitos & $\begin{array}{l}\text { Activos: desetilcloroquina } \\
\text { y bisdesetil cloroquina } \\
\text { Otros menores: } 7 \text {-cloro } \\
\text { 4-aminoquinolina y otros (22) }\end{array}$ & $\begin{array}{l}\text { Activos: N-desetil amodiaquina. } \\
\text { Otros menores: 2-hidroxildes- } \\
\text { amodiaquina, N-bisdesetil } \\
\text { amodiaquina (21) }\end{array}$ & $\begin{array}{l}\text { Carboximefloquina } \\
\text { (inactivo) (29) }\end{array}$ & $\begin{array}{l}\text { Activos: cicloguanil. } \\
\text { Otros menores: } \\
\text { 4-clorofenilbiguanida } \\
\text { (inactivo) (30) }\end{array}$ \\
\hline Vías & $\begin{array}{l}\text { Desaminación oxidativa, } \\
\text { eliminación de la cadena } \\
\text { lateral y otras vías } \\
\text { N-oxidativas (22) }\end{array}$ & $\begin{array}{l}\text { Eliminación de la cadena lateral } \\
\text { y otras vías } \mathrm{N} \text {-oxidativas (21) }\end{array}$ & Carboxilación (29) & \\
\hline $\begin{array}{l}\text { Toxicidad de las dosis } \\
\text { antimaláricas }\end{array}$ & Mínima (20) & Poca & $\begin{array}{l}\text { Náuseas, vómitos, dolor } \\
\text { abdominal, diarrea, } \\
\text { mareo (6) }\end{array}$ & Poca (30) \\
\hline Desnutrición & $\begin{array}{l}\text { Niños: volumen de } \\
\text { distribución y eliminación } \\
\text { hepática (27) } \\
\text { Adultos: sin cambios (28) }\end{array}$ & $\ldots$ & $\ldots$ & $\ldots$ \\
\hline Enzimas inhibidas & CYP2D6 (20) & Sin datos & CYP1A2 & Sin datos \\
\hline
\end{tabular}

${ }^{a}$ Las fuentes bibliográficas aparecen entre paréntesis.

${ }^{b}$ La dosis total se fracciona en 3 días: 10, 7,5 y $7,5 \mathrm{mg} / \mathrm{kg} \mathrm{d}^{-1}$, pero nunca es mayor de $1500 \mathrm{mg}$ (26).

${ }^{c}$ La dosis total se fracciona en 3 días: 10,10 y $5 \mathrm{mg} / \mathrm{kg} \mathrm{d}^{-1}$, pero nunca es mayor de $1500 \mathrm{mg}$ (26). 
la sangre). Aunque ambos medicamentos son activos en su forma original, la actividad antimalárica de sus metabolitos iniciales - la desetil-AQ y la desetil-CQ - es mucho mayor. Por el contrario, la MQ es activa en su forma original y su primer metabolito - la carboxi-MQ - no tiene actividad antimalárica. Aunque el PG es poco activo en su estado original, su metabolito - el cicloguanil- tiene una gran actividad. La enzima CYP2C8 participa en el metabolismo de la AQ y de la $C Q$, mientras que la CYP2D6 actúa sobre la CQ y la CYP3A4 transforma la CQ y la MQ. Por su parte, las enzimas CYP2A4 y CYP2C19 metabolizan el PG.

Hasta hace algunos años, la CQ era el medicamento de elección contra la malaria en todo el mundo, por lo que existe una abundante información sobre su acción clínica y su farmacocinética. Aunque todavía es el medicamento más frecuentemente empleado en el tratamiento de la malaria por $P$. vivax, se usa cada vez menos en casos producidos por $P$. falciparum (31). También se usa como antirreumático (32).

La tasa de fracaso terapéutico de la combinación AQ-sulfadoxina-pirimetamina en pacientes con malaria por
P. falciparum ha sido baja en África (33) y muy baja en Colombia, donde el fracaso de esta combinación es solo de $2 \%$ (34). La vía principal de eliminación sistémica de la $A Q$ del organismo humano es su transformación en desetilamodiaquina, por el efecto del primer paso de la acción de la CYP2C8 (antes se le atribuía a la CYP3A4) en el hígado (21). La modificación de la actividad de la CYP2C8 por la administración de fármacos inhibidores, la ingestión combinada de inhibidores e inductores presentes en la dieta y el polimorfismo genético podrían estar relacionados con las diferencias observadas entre los parámetros cinéticos de diferentes personas. Esto podría tener una importante implicación en las respuestas terapéutica y toxicológica.

La MQ es un fármaco sintético (arilaminoalcohol) empleado como profiláctico y en el tratamiento de la malaria, aunque recientemente se encontraron tasas de curación de solo $41 \%$ en Asia (35). Aunque el fracaso terapéutico con la MQ como monoterapia fue solamente de $4 \%$ en 2004 (datos sin publicar de los autores), se recomienda aplicarla en combinación con uno o varios medicamentos. En cuanto a su metabolismo, la MQ se trans- forma en carboximefloquina, que se excreta principalmente con las heces y en menor cantidad por la orina (17). El efecto de la enfermedad malárica sobre el metabolismo de este medicamento aún no se conoce totalmente (29), aunque se sabe que los efectos adversos dependen de la dosis y desaparecen espontáneamente (36).

El PG es una biguanida que inhibe la acción de la enzima dihidrofolato reductasa producida por el parásito. El uso terapéutico y profiláctico del PG se ha visto limitado por la rápida emergencia de la resistencia de $P$. falciparum. El PG se transforma en el hígado y se convierte en el metabolito activo cicloguanil y luego en el 4-clorofenilbiguanida, que no tiene actividad antimalárica. Tanto cuando se administra con la CQ con fines profilácticos (37) como cuando se combina con la atovacuona para el tratamiento (38), el PG produce dolor abdominal y vómitos.

Estudios de la farmacocinética de los medicamentos antimaláricos metabolizados por el CYP-450 que fueron administrados por vía oral a personas sin malaria demuestran que la concentración máxima $\left(C_{\max }\right)$ plasmática de la $C Q$ después de una dosis de $300 \mathrm{mg}$ (que es menos de la mitad de los $750 \mathrm{mg}$ que

CUADRO 3. Farmacocinética de medicamentos antimaláricos orales metabolizados por el citocromo P-450 en personas sin malaria

\begin{tabular}{|c|c|c|c|c|c|c|c|c|c|c|}
\hline $\begin{array}{l}\text { Medica- } \\
\text { mento }^{a}\end{array}$ & $\begin{array}{c}\text { No. } \\
\text { de } \\
\text { muestras }\end{array}$ & $\begin{array}{c}\text { Tipo } \\
\text { de } \\
\text { muestra }\end{array}$ & $\begin{array}{c}\text { Dosis } \\
\text { total } \\
(\mathrm{mg})\end{array}$ & $\mathrm{C}_{\text {máx }}{ }^{\mathrm{b}}(\mathrm{mg} / \mathrm{L})$ & $\mathrm{t}_{\text {máx }}{ }^{\mathrm{c}}(\mathrm{h})$ & $\begin{array}{c}\text { Vida } \\
\text { media } \\
\text { (h) }\end{array}$ & $\begin{array}{c}\text { Área } \\
\text { bajo } \\
\text { la curva } \\
\left(\mathrm{ng} / \mathrm{h} \mathrm{mL}^{-1}\right)\end{array}$ & $\begin{array}{c}\text { Volumen } \\
\text { de } \\
\text { distribución } \\
(\mathrm{L} / \mathrm{kg})\end{array}$ & $\begin{array}{l}\text { Eliminación } \\
\left(\mathrm{mL} / \mathrm{min}^{-1}\right)\end{array}$ & $\begin{array}{l}\text { Referen- } \\
\text { cia }\end{array}$ \\
\hline $\mathrm{CQ}$ & 8 & Plasma & 310 & $\ldots$ & $\ldots$ & $144-168$ & $\ldots$ & $\ldots$ & $\ldots$ & (39) \\
\hline $\mathrm{CQ}$ & 11 & Plasma & 300 & $73 \pm 12$ & $3,3 \pm 1,9$ & $205 \pm 59$ & $4990 \pm 879$ & $\ldots$ & $\ldots$ & (40) \\
\hline $\mathrm{CQ}$ & 11 & Plasma & 300 & $76 \pm 14$ & $3,6 \pm 2$ & $275 \pm 111$ & $6111 \pm 1315$ & $\ldots$ & $\ldots$ & (40) \\
\hline $\mathrm{CQ}$ & 6 & Plasma & 600 & $\ldots$ & $\ldots$ & $75 \pm 30$ & $\ldots$ & $\ldots$ & $\ldots$ & $(41)$ \\
\hline $\mathrm{CQ}$ & 6 & Plasma & 600 & $286 \pm 73$ & $2,8 \pm 1,3$ & $191 \pm 69$ & $20335 \pm 6071$ & $\ldots$ & $\ldots$ & (41) \\
\hline $\mathrm{CQ}$ & 3 & Plasma & 600 & $374 \pm 56$ & $5,0 \pm 3,0$ & $192 \pm 28$ & $18609 \pm 4254$ & $\ldots$ & $\ldots$ & (42) \\
\hline $\mathrm{CQ}$ & 7 & Plasma & 600 & 364 & $5,1 \pm 2,8$ & $190 \pm 27,7$ & $\ldots$ & $\ldots$ & $\ldots$ & (43) \\
\hline $\mathrm{CQ}$ & 5 & Plasma & 200 & 244 & 3,2 & $50 \pm 16$ & $\ldots$ & $\ldots$ & $\ldots$ & (44) \\
\hline $\mathrm{CQ}$ & 7 & Plasma & 600 & 838 & $\ldots$ & 150 & 122000 & $\ldots$ & $\ldots$ & (45) \\
\hline$A Q$ & 7 & Plasma & 600 & $32 \pm 8$ & $5,2 \pm 4,5$ & $\ldots$ & $154 \pm 38$ & $\ldots$ & $\ldots$ & $(46)$ \\
\hline$M Q$ & 12 & $\ldots$ & 1250 & $2,30 \pm 0,750$ & $15,9 \pm 4,5$ & $12,5 \pm 3,2$ días & $21780 \pm 5990$ & $23,7 \pm 3,4$ & $0,899 \pm 0,23$ & (47) \\
\hline$P G$ & 6 & $\cdots$ & 400 & $\begin{array}{c}1201,6 \pm 132,4 \mathrm{nmol} / \mathrm{L} \\
317 \pm 44,4\end{array}$ & $\cdots$ & $\cdots$ & $\cdots$ & $\cdots$ & $\ldots$ & $(48)$ \\
\hline PG & 6 & $\ldots$ & 200 & $\begin{array}{l}0,13 \pm 0,016 \\
0,52 \pm 0,152\end{array}$ & $\begin{array}{c}3,8 \pm 1,3 \\
5,3 \pm 1\end{array}$ & $\begin{array}{c}14,5 \pm 3 \\
11,7 \pm 3,1\end{array}$ & $\ldots$ & $30,7 \pm 12,3$ & $\begin{array}{c}1,43 \pm 0,33 \\
\mathrm{~L} / \mathrm{h} \mathrm{kg}^{-1}\end{array}$ & (25) \\
\hline
\end{tabular}

\footnotetext{
a $\mathrm{CQ}$ : cloroquina; $\mathrm{AQ}$ : amodiaquina; $\mathrm{MQ}$ : mefloquina; $\mathrm{PG}$ : proguanil.

${ }^{\text {b }} C_{\text {máx }}$ : concentración máxima.

${ }^{c} t$ máx: tiempo en que se alcanza la concentración máxima.
} 
CUADRO 4. Farmacocinética de la cloroquina, amodiaquina y mefloquina en pacientes con malaria por Plasmodium falciparum sin complicaciones

\begin{tabular}{|c|c|c|c|c|c|c|c|c|}
\hline Medicamento & $\begin{array}{l}\text { No. de } \\
\text { muestras }\end{array}$ & $\begin{array}{l}\text { Tipo de } \\
\text { muestra }\end{array}$ & $\begin{array}{l}\text { Dosis } \\
\text { total } \\
(\mathrm{mg} / \mathrm{kg})\end{array}$ & $\begin{array}{l}C_{\operatorname{máx}}^{b} \\
(\mathrm{mg} / \mathrm{L})\end{array}$ & $t_{\text {máx }}^{c}(\mathrm{~h})$ & $\begin{array}{l}\text { Vida } \\
\text { media } \\
\text { (días) }\end{array}$ & $\begin{array}{l}\text { Área bajo } \\
\text { la curva } \\
\left(\mathrm{ng} / \mathrm{h} \mathrm{mL}^{-1}\right)\end{array}$ & Referencia \\
\hline Amodiaquina & 14 & Plasma & 10 & $21 \pm 11$ & $105 \pm 72$ & $3,7 \pm 1$ & $77 \pm 46$ & (50) \\
\hline Desamodiaquina & 14 & Plasma & $\ldots$ & $161 \pm 72$ & $234 \pm 72$ & $\ldots$ & $621 \pm 249$ & (50) \\
\hline Mefloquina $^{a}$ & 257 & $\ldots$ & 25 & $\ldots$ & $\ldots$ & $\ldots$ & $46,21-55,17 \mathrm{ng} / \mathrm{mL} \mathrm{d}^{-1}$ & (51) \\
\hline
\end{tabular}

a El volumen de distribución de $\mathrm{MQ}$ es de 20,37 a $25,51 \mathrm{~L} / \mathrm{kg}$ y su tasa de eliminación es de $3 \pm 0,3 \mathrm{~mL} / \mathrm{min}^{\mathrm{kg}}{ }^{-1}$.

${ }^{\text {b }} C_{\text {máx: }}$ : concentración máxima.

${ }^{c} t_{\text {máx }}$ : tiempo en que se alcanza la concentración máxima

toma un adulto con malaria en el primer día de tratamiento) alcanza generalmente valores de $76 \pm 14 \mathrm{mg} / \mathrm{L}$ y que el tiempo máximo $\left(t_{\max }\right)$ en que se alcanza esa concentración es de 3,6 $2 \pm 2$ h (cuadro 3). Cuando la dosis es de $600 \mathrm{mg}$, la $C_{\max }$ es de $374 \pm 56 \mathrm{mg}$ y el $t_{\max }$ es de 5,0 \pm $3,0 \mathrm{~h}$ (16). Como se ilustra en el cuadro 4, los parámetros farmacocinéticos de los antimaláricos sufren modificaciones durante la enfermedad.

Se debe destacar que las variables que caracterizan la farmacocinética de los medicamentos cambian de acuerdo con la actividad del complejo enzimático del CYP-450, por lo que ambos factores se deben tomar en cuenta para explicar la respuesta terapéutica antimalárica y los efectos tóxicos de esos medicamentos.

Es importante resaltar que algunos medicamentos antimaláricos provocan la inhibición o inducción de algunas de las enzimas del complejo del CYP450. Por ejemplo, la CQ y la halofantrina inhiben la acción de la CYP2D6, la MQ inhibe la acción de la CYP1A2 y la primaquina es un potente inhibidor de la actividad de la CYP3A4. Además, la quinina, la primaquina y el albendazol inducen (a nivel transcripcional) la actividad de las enzimas CYP1A1 y CYP1A2. Estos elementos deben tenerse en cuenta al formular combinaciones de antimaláricos $\mathrm{o}$ cuando se adicionan al tratamiento otros medicamentos (analgésicos, antibióticos, etc.), lo que ocurre frecuentemente al tratar pacientes con malaria.

Se ha avanzado mucho en el estudio de las bases moleculares de la resistencia a algunos medicamentos, como la sulfadoxina y la pirimetamina, y se sabe que determinadas mutaciones puntuales en el genoma del parásito están asociadas con esa resistencia y con el fenotipo vinculado con el fracaso terapéutico in vivo (52). Sin embargo, no se conocen marcadores genéticos asociados claramente con la respuesta terapéutica de otros importantes medicamentos antimaláricos, como la CQ, AQ y la MQ (33).

Como se ha visto, la farmacocinética y la farmacodinamia de los antimaláricos dependen del fármaco, del estado de salud de la persona (enfermos con malaria o personas sanas) y del consumo simultáneo de otros medicamentos. Se desconoce si los factores que estimulan o inhiben la actividad de las enzimas de este complejo pueden alterar la respuesta terapéutica, pero es lógico suponer que así sea. El papel de este complejo enzimático en la respuesta terapéutica antimalárica aún no está totalmente estudiado y solo en los dos últimos años se han podido identificar los citocromos que intervienen en el metabolismo de la $C Q$ y de la $A Q$.

En el presente trabajo se evalúa la relación entre los factores genéticos y fenotípicos del sistema del CYP-450 y la respuesta terapéutica antimalárica a la $C Q$, la $A Q$, la MQ y el PG, y también se determina la influencia de algunos factores biológicos y sociales del hos-

\footnotetext{
http://www.ncbi.nlm.nih.gov/entrez/query.fcgi 3 http://www.embase.com/

4 http://bases.bireme.br/cgi-bin/wxislind.exe/ iah/online/

5 http://www.scielo.br
}

pedero en el comportamiento de este complejo enzimático.

\section{MATERIALES Y MÉTODOS}

Para la presente revisión sistemática se examinaron las principales bases de datos bibliográficas de la literatura biomédica mediante palabras clave o descriptores específicos. Se buscaron todos los artículos de investigación y de revisión publicados en español, portugués o inglés antes del 30 de junio de 2005. Las bases de datos investigadas fueron PubMed (MEDLINE) ${ }^{2}$, Embase (Excerpta Medica) ${ }^{3}$, LILACS $^{4}$ y Scientific Electronic Library Online (SciELO) ${ }^{5}$.

Se usaron los siguientes descriptores: "CYP-450" y "citocromo P-450" y sus combinaciones con "proguanil" (y lo mismo con "mefloquina", "cloroquina" y "amodiaquina"), "farmacocinética de proguanil" (y lo mismo con "mefloquina", "cloroquina" y "amodiaquina"), "resistencia a proguanil" (y lo mismo con "mefloquina", "cloroquina" y "amodiaquina"), "metabolismo", "farmacogenética", "enfermedad", "inflamación", "infección", "enfermedad hepática", "malaria", "nutrición" y "desnutrición". Estos mismos términos se usaron en inglés 6 .

\footnotetext{
"CYP-450" y "cytochrome P-450" y sus combinaciones con "proguanil" ("mefloquine", "chloroquine" "amodiaquine"), "pharmacokinetics of proguanil" ("mefloquine", "chloroquine", "amodiaquine"), "resistance to proguanil" ("mefloquine", "chloroquine", "amodiaquine"), "metabolism", "pharmacogenetics", "disease"; "inflammation", "infection", "hepatic disease", "malaria", "nutrition" y "malnutrition".
} 
Para la revisión sistemática sobre la relación entre el fenotipo y genotipo del CYP-450 y la respuesta terapéutica antimalárica se analizaron solo los estudios epidemiológicos en humanos. También se realizó una revisión descriptiva acerca de los efectos de la infección, la inflamación y la malaria sobre el funcionamiento del CYP-450 y los factores que modifican su actividad.

El estudio de la relación entre la actividad del CYP-450 y el tratamiento se limitó a cuatro medicamentos antimaláricos: $\mathrm{AQ}, \mathrm{CQ}, \mathrm{MQ}$ y PG. La AQ es el medicamento de primera elección para el tratamiento de la malaria por $P$. falciparum en Colombia y en algunos países africanos, donde su alta eficacia es cada vez más reconocida. El PG, aunque no se emplea como monoterapia para el tratamiento antimalárico, es un patrón de referencia del metabolismo y de los blancos terapéuticos de la pirimetamina (medicamento usado junto con la AQ y la sulfadoxina) para el tratamiento de la malaria causada por $P$. falciparum). La MQ se utiliza ampliamente en Asia y su empleo aumenta en el resto de los países donde hay malaria endémica —especialmente para sustituir a la CQ-, por lo general en combinación con la sulfadoxina y la pirimetamina. La CQ es el medicamento de primera elección para tratar la malaria causada por $P$. vivax en todo el mundo, aunque en la actualidad se emplea poco en el tratamiento de la malaria producida por $P$. falciparum.

\section{RESULTADOS}

\section{Relación entre la respuesta terapéutica y el CYP-450}

En total se hallaron 21 artículos que relacionaban los efectos de la malaria y la infección parasitaria con la actividad del CYP-450; de estos, solo dos trabajos de investigación abordaron la relación entre la respuesta terapéutica antimalárica y las características fenotípicas y genotípicas del CYP-450 $(53,54)$.

En el estudio de Kaneko et al. (53), realizado en Vanuatu, Melanesia, se estudió a 95 pacientes con malaria que recibieron tratamiento con PG. Se en- contró que algunas mutaciones en el gen CYP2C19 hicieron más lento el metabolismo del PG a cicloguanil, que se considera su forma activa contra la infección por Plasmodium. Sin embargo, estos pacientes lograron inhibir el crecimiento del parásito, lo que demuestra que existe una eficacia intrínseca del PG y que su conversión a cicloguanil no es imprescindible para lograr eliminar el parásito.

La investigación de Cavaco et al. (54) se llevó a cabo en 165 enfermos de malaria, sin consanguinidad entre sí, residentes en la isla Zanzíbar, Tanzanía, donde la $A Q$ es el tratamiento de primera elección para esta enfermedad y se emplea en alrededor de un millón de casos cada año. En los pacientes con metabolismo lento, el medicamento permanece más tiempo en los tejidos, lo que aumenta el riesgo de sufrir efectos adversos. El hecho de que $3,6 \%$ de los pacientes estudiados resultaran homocigotos con el genotipo metabolizador lento puede indicar que alrededor de 36000 de los pacientes que reciben $\mathrm{AQ}$ cada año en Zanzíbar tienen un riesgo elevado de sufrir efectos adversos.

\section{Factores que modifican la actividad del CYP-450}

Algunos factores genéticos (principalmente el polimorfismo genético) y biológicos o sociales inhiben o estimulan la actividad del CYP-450. Entre estos últimos se encuentran la propia enfermedad, los medicamentos antimaláricos y su combinación, la inflamación, la infección y el estado nutricional del paciente. A continuación se analizan en detalle estos elementos, por la influencia que ejercen en la relación entre la actividad del CYP-450 y la malaria, especialmente en las zonas endémicas donde esta enfermedad va acompañada casi siempre de otras infecciones parasitarias y de desnutrición.

La inhibición de la actividad de la enzima involucrada en el metabolismo de un medicamento dado puede hacer más lento ese proceso, con lo que se reduciría la concentración del metabolito antimalárico necesaria para eliminar el pa- rásito. Por su parte, la estimulación de la actividad de algunas de esas enzimas también puede ser perjudicial, ya que se podría acelerar la conversión del medicamento en su metabolito inactivo y favorecer su rápida excreción o la acumulación de algunos derivados tóxicos que provoquen reacciones adversas $(55,56)$. Además, el consumo simultáneo de medicamentos puede estimular o inhibir la actividad del CYP-450 por la unión del modulador al sitio activo de la proteína o al grupo hemo (56).

Variación genética. El CYP-450 presenta una gran variación genética (57). Hasta ahora se han descrito variantes alélicas en los genes CYP1A1, CYP1A2, CYP1B1, CYP2A6, CYP2A13, CYP2B6, CYP2C8, CYP2C9, CYP2C19, CYP2D6, CYP2E1, CYP3A4 y CYP3A5, entre otros (58). Se debe resaltar que a pesar de que estas variantes no se han asociado con la respuesta terapéutica antimalárica, sí están relacionadas con la disminución de la respuesta terapéutica a varios medicamentos $(59,60)$. Algunas variantes alélicas importantes asociadas con la evolución de la enfermedad y con el efecto de los medicamentos antimaláricos son:

- Las variantes alélicas $C Y P 2 C 8^{*} 2$ y CYP2C $8 * 3$ están asociadas con el metabolismo incompleto (reducción de la eliminación intrínseca) del medicamento anticanceroso paclitaxel $\left(\mathrm{Taxol}^{\mathrm{R}}\right)$ y del ácido araquidónico, con solo 15 y $35 \%$, respectivamente, de la actividad del CYP2C $8^{*} 1$, que es el tipo silvestre ("normal") (60). Esas variantes se encuentran en $18 \%$ y $13 \%$, respectivamente, de los estadounidenses de origen africano (60). La enzima CYP2C8 participa en el metabolismo de la AQ y la CQ.

- La enzima CYP2C9 interviene en el metabolismo de diversos medicamentos, entre ellos de la fenitoína, la warfarina, la tolbutamida, el diclofenaco, el ibuprofeno, el ácido acetilsalicílico y la naftoquinona (este último empleado como antimalárico) (59). La variante alélica CYP2C9*2 se encuentra en 11-13\% de los pacientes caucásicos y en 1-4\% de los de origen africano $(60,61)$. 
- Se ha encontrado una elevada frecuencia de variaciones alélicas del gen CYP2C19 en la población de Vanuatu, en Melanesia, donde casi la totalidad de la población presenta el fenotipo metabolizador lento (30, 62). En estas islas, la malaria es endémica y se utilizan varios medicamentos antimaláricos metabolizados por esta enzima para controlar la enfermedad. El polimorfismo de esta enzima puede afectar a la respuesta terapéutica al PG (30).

- Se han encontrado varias formas mutantes del gen CYP2D6 entre los metabolizadores rápidos y lentos. Aún no se conoce el papel que desempeña esta enzima en el metabolismo de la halofantrina; sin embargo, se ha observado que la administración de la quinidina y de la lumefantrina inhibió la actividad de esta enzima en voluntarios sanos $(17,63)$.

La subfamilia CYP3A (CYP3A4, CYP3A5, CYP3A7, CYP3A43) es una de las más importantes en la biotransformación de los medicamentos. Se ha detectado su ARNm en todos los adultos estudiados hasta este momento, aunque no se conoce de un alelo null para el gen CYP3A4 (14). Se han identificado 40 variantes alélicas del gen que codifica la enzima CYP3A4, de las cuales la más frecuente es la $C Y P 3 A 4^{*} 1 B$ (14). De las variantes estructurales de esta enzima identificadas hasta el momento, ninguna presenta una mutación que comprometa el dominio de la unión al sustrato putativo (14). La variante alélica CYP $3 A 4^{*} 1 B$ se distribuye desigualmente entre los estadounidenses de origen africano $(63 \%)$, caucásico $(11 \%)$ e hispano (9-11\%) (14). La actividad catalítica y las bajas frecuencias alélicas de las variantes estructurales de la enzima CYP3A4 hacen pensar que los factores genéticos no son los responsables principales de las diferencias encontradas en la tasa de depuración de los medicamentos dependientes de la enzima CYP3A4 en diferentes personas y que otros factores pueden desempeñar un papel importante. Quiere decir que el metabolismo incompleto de algunos medicamentos metabolizados por esta vía no se puede explicar mediante la presencia de variantes polimórficas, sino, probablemente, de una interacción entre los medicamentos empleados.

De los diferentes factores, el polimorfismo genético de las enzimas que participan en la biotransformación de los medicamentos desempeña el papel principal en la variabilidad del metabolismo de los medicamentos observada en diferentes personas, así como en los efectos tóxicos de algunos medicamentos y su fracaso terapéutico. Esta variación genética permite clasificar a la población en tres grupos: metabolizadores lentos, rápidos y ultrarrápidos. Esta distinción se realiza generalmente según la relación entre la cantidad de medicamento en su forma original y su respectivo metabolito en la orina (59). Se debe aclarar que las variaciones genéticas no siempre explican la modificación de la enzima, ya que algunas mutaciones no comprometen su sitio activo y aunque modifiquen el fenotipo enzimático, este solamente se expresa cuando la persona se expone al medicamento o producto xenobiótico metabolizado por esa enzima.

La infección y la inflamación. Las infecciones y los estados inflamatorios producen cambios en la actividad y la expresión de varias formas hepáticas y extrahepáticas del CYP-450, como las observadas en el cerebro y el riñón. Esto puede deberse a que en algunos casos el hígado destina su maquinaria transcripcional a la síntesis de las proteínas de fase aguda, necesarias para el control de la respuesta inflamatoria sistémica (64). Algunos factores humorales y celulares, como el lipopolisacárido usado en algunos modelos de septicemia, ayudan a reducir la actividad del CYP-450 inhibiendo la expresión de las enzimas CYP1A, CYP2B, CYP3A y CYP4A. Al parecer, las citocinas que participan en este proceso son el factor de necrosis tumoral $\alpha$, la interleucina 6 , además del antígeno CD14 $(64,65)$.

Otros componentes pueden desempeñar también un papel importante en la modulación de la actividad del CYP-450, además de las citocinas. El estímulo inflamatorio produce cambios en las concentraciones séricas de glucocorticoides. Estos corticoides ejercen un doble efecto sobre la expresión del ARNm necesario para la síntesis de la enzima CYP2C11 en los hepatocitos: por una parte la estimulan si hay bajas concentraciones (reposo) y por otra, la inhiben si hay altas concentraciones (estrés) (64).

El proceso inflamatorio provocado por las infecciones, entre ellas la malaria, reduce la actividad del complejo enzimático del CYP-450. En las zonas con malaria endémica es frecuente encontrar otras infecciones parasitarias y desnutrición, por lo que el efecto inhibidor ejercido por la infección y la inflamación sobre la actividad del CYP-450 se mantiene permanentemente. Los estudios que examinan la relación entre la eficacia terapéutica de los medicamentos, la actividad del CYP-450 y la presencia de inflamación son pocos, por lo que se deben diseñar estudios farmacoterapéuticos que profundicen en estos aspectos.

Efecto de la enfermedad malárica (estudios hechos en animales). La malaria causada por $P$. berghei o por $P$. yoelli en ratas y ratones produce una fuerte reducción de la actividad del CYP-450, medida tanto in vivo como en mitocondrias y microsomas hepáticos cultivados in vitro. Los elementos de mayor interés encontrados en los artículos de investigación que abordaron este tema (cuadro 5) son los siguientes:

a) Un estudio del efecto de la infección por $P$. berghei en el metabolismo mediado por las enzimas CYP2E1 y CYP3A2 en microsomas hepáticos de ratones infectados demostró una reducción de $56 \%$ en la cantidad de citocromo expresada, de $32 \%$ en la actividad de la enzima dinucleótido fosfato de nicotinamida y adenina (NADPH) reductasa del CYP-450, y de $41 \%$ en la actividad de la $6-\beta$ hidroxilasa de testosterona (correspondiente a la CYP3A2), aunque no afectó a la 4-clorozoxazonehidroxilasa (correspondiente a la CYP2E1) (66).

b) La actividad de las enzimas del CYP-450 microsómicas hepáticas y, especialmente, la de las mitocondriales disminuye cuando hay infección por $P$. berghei y $P$. yoelli. 


\section{CUADRO 5. Efectos de la infección malárica en la actividad del citocromo P-450}

\begin{tabular}{|c|c|c|c|c|c|}
\hline Animal & Sistema & Agente infeccioso & Efecto & Enzima o proceso metabólico & Referencias \\
\hline Rata & & & Ninguno & 4-clorozoxazonehidroxilasa (CYP2E1) & \\
\hline Ratón & $\begin{array}{l}\text { Mitocondrias y } \\
\text { microsomas hepáticos }\end{array}$ & Plasmodium yoelli & Decae la actividad & Citocromo-450, citocromo b5 & (67) \\
\hline \multirow[t]{2}{*}{$\begin{array}{l}\text { Mastomys } \\
\text { nata-lensis }\end{array}$} & Microsomas hepáticos & Plasmodium berghei & $\begin{array}{l}\text { Decae la actividad en cepas } \\
\text { sensibles }\end{array}$ & Hemoxigenasas & (69) \\
\hline & & & $\begin{array}{l}\text { Decae la actividad en cepas } \\
\text { resistentes }\end{array}$ & Hemoxigenasas & \\
\hline Ratón & Microsomas hepáticos & Plasmodium berghei & $\begin{array}{l}\text { Decae la actividad después } \\
\text { de } 6 \text { semanas con cloroquina }\end{array}$ & Hemoxigenasas y hemo & (70) \\
\hline Rata & Microsomas hepáticos & Plasmodium spp. & Decae la actividad & $\begin{array}{l}\text { Alteración de la actividad de la UDP- } \\
\text { glucuronosiltransferasa }\end{array}$ & (72) \\
\hline Rata & Microsomas hepáticos & Plasmodium berghei & Decae la actividad & $\begin{array}{l}\text { Reducción de la eliminación del } \\
\text { paracetamol }\end{array}$ & (73) \\
\hline Rata & In vivo & Plasmodium berghei & Decae la actividad & Metabolismo de la cafeína & (74) \\
\hline \multirow[t]{3}{*}{ Rata } & In vivo & Plasmodium berghei & Ninguno & Metabolismo de la antipirina & (75) \\
\hline & & & Decae la actividad $20 \%$ & Metabolismo del metronidazol & \\
\hline & & $\begin{array}{l}\text { Escherichia coli } \\
\text { enterotoxígena }\end{array}$ & $\begin{array}{l}\text { Decae la actividad entre } 36 \\
\text { y } 23 \%\end{array}$ & $\begin{array}{l}\text { Metabolismo de la antipirina y del } \\
\text { metronidazol }\end{array}$ & \\
\hline \multirow[t]{2}{*}{ Rata } & Preparación de hígado & Plasmodium berghei & Decae la actividad & $\begin{array}{l}\text { Eliminación y volumen de distribución de la } \\
\text { quinina. Eliminación y prolongación de la } \\
\text { hemivida de la quinidina }\end{array}$ & (78) \\
\hline & & & Ninguno & Hemivida de la quinina & \\
\hline Rata & Hepatocitos aislados & Plasmodium berghei & Decae la actividad & $\begin{array}{l}\text { Eliminación hepática de la primaquina con } \\
\text { el incremento de la parasitemia }\end{array}$ & (79) \\
\hline Ratón & Microsomas hepáticos & $\begin{array}{l}\text { Plasmodium yoelli } \\
\text { nigeriensis }\end{array}$ & Decae la actividad & $\begin{array}{l}\text { Anilina hidroxilasa, aminopirina-N- } \\
\text { demetilasa, benzo(a)pireno hidroxilasa, } \\
\text { reductasa del citocromo b5, reductasa del } \\
\text { citocromo c, citocromo b5 y glucosa-6- } \\
\text { fosfatasa }\end{array}$ & (80) \\
\hline \multirow[t]{2}{*}{ Ratón } & Hepatocitos aislados & Plasmodium berghei & Decae la actividad & Citocromo-450 & (81) \\
\hline & & & Decae la actividad $30-40 \%$ & $\begin{array}{l}\text { Metabolismo de etilmorfina y } \\
\text { benzo(a)pireno en fase eritrocítica pero no } \\
\text { hepática }\end{array}$ & \\
\hline Rata & Microsomas hepáticos & Endotoxina & Decae la actividad & CYP3A4, metabolismo de la lidocaína & $\begin{array}{l}\text { (82) } \\
\text { (Continúa) }\end{array}$ \\
\hline
\end{tabular}


CUADRO 5. (Continuación)

\begin{tabular}{|c|c|c|c|c|c|}
\hline Animal & Sistema & Agente infeccioso & Efecto & Enzima o proceso metabólico & Referencias \\
\hline
\end{tabular}

c) La evaluación del estado del CYP450, del citocromo b5, del grupo hemo y de la hemozoína (pigmento malárico tóxico para el parásito) en ratones infectados por $P$. yoelii tratados con pirimetamina demostró que tanto la actividad microsomal como la mitocondrial del CYP-450 y del citocromo b5 se reducen notablemente durante la infección y que estas reducciones se incrementan de forma proporcional según el grado de parasitemia. El tratamiento con pirimetamina oral redujo la parasitemia a las 72 horas, a medida que se normalizaba la actividad de los citocromos en ambas fracciones (microsómica y mitocondrial) (67).

Otros estudios que examinan la relación entre la malaria y la actividad del CYP-450 en monos han demostrado que el grupo hemo afecta a la estructura del CYP-450 microsómico (86). Uno de los mecanismos propuestos para explicar esta reducción de la actividad enzimática está relacionado con el efecto del grupo hemo y de la hemozoína sobre diferentes vías metabólicas, entre ellas la oxidación microsómica (70). Otra explicación puede ser la reducción observada en la síntesis de las enzimas necesarias para formar y ensamblar el sistema de oxidación microsómica (71), pues en ratones con infección aguda por el virus Coxsackie B3, el proceso de desintoxicación disminuye en favor de la síntesis de proteínas de la fase aguda (85). La infección por $P$. berghei inhibe parcialmente la síntesis de las enzimas S-aminolevulínicosintetasa, S-aminolevulínicodeshidratasa ácida $\mathrm{y}$, finalmente, la ferroquelatasa, las cuales participan de una forma $u$ otra en el establecimiento del complejo enzimático del CYP-450 (87).

La información derivada de los estudios con modelos basados en animales indica que la infección y la inflamación propias de la malaria reducen la actividad del sistema del CYP-450. Esto pudiera afectar al metabolismo de los medicamentos antimaláricos, muchos de los cuales necesitan ese sistema enzimático para convertirse en metabolitos activos capaces de matar el parásito. Al mismo tiempo, otros medicamentos antimaláricos pasan a ser formas inactivas, de manera que la acumulación del fármaco activo produce mayores concentraciones antiplasmódicas, pero eleva el riesgo de sufrir efectos adversos. El metabolismo de los medicamentos antimaláricos en los modelos con animales es muy similar al observado en seres humanos.

La hepatitis provocada por la malaria también puede alterar la farmacocinética de los compuestos antimaláricos. En un estudio realizado recientemente se encontró que la $\mathrm{AQ}$ se elimina activamente en el hígado $(>70 \%)$, mientras que la artemisinina, el artesunato y la quinina son de eliminación intermedia $(30-70 \%)$ y la CQ, la pirimetamina y la dapsona se eliminan poco $(<30 \%)$ (18). Según estos datos, la inflamación hepática puede ser uno de los factores que explican la gran variabilidad farmacocinética descrita en los pacientes tratados con AQ (21).

Efecto de los antimaláricos. Frecuentemente se combinan diversos medicamentos para tratar la malaria, principalmente con el objetivo de re- ducir o al menos retrasar la aparición de la resistencia a los diversos fármacos. La experiencia en el empleo de diferentes combinaciones de medicamentos ha permitido llegar a algunas conclusiones:

a) Las combinaciones basadas en $\mathrm{AQ}$ y MQ influyen poco en el funcionamiento del sistema enzimático del CYP-450, como se observa en el tratamiento combinado con la sulfadoxina y la pirimetamina. Esto puede deberse a que la MQ y la AQ se metabolizan por vías distintas a la empleada por estas últimas (17).

b) La CQ mejora la función del CYP450 (67).

c) La QN inhibe la actividad de la enzima CYP2A6, que participa en el metabolismo del anticoagulante $\mathrm{cu}^{-}$ marina (88).

d) La halofantrina y la CQ, metabolizadas por la enzima CYP3A4, inhiben la actividad enzimática de la CYP2D6, encargada del metabolismo de la debrisoquina (89).

e) El antimicótico ketoconazol inhibe fuertemente la actividad de las enzimas CYP3A4, CYP1A2 y CYP2D6, que participan en el metabolismo de la PQ (90).

f) El metabolismo de Plasmodium puede controlarse con medicamentos, lográndose revertir su resistencia a la $C Q$, tal como ocurre in vitro con la cimetidina y el verapamilo. Estos medicamentos inhiben la actividad enzimática del complejo del CYP$450(90,91)$. Al parecer, el incremento en la expresión de estas enzimas podría acelerar el proceso mediante el cual el parásito logra eliminar el antimalárico (92). 
El conocimiento de las enzimas que participan en el metabolismo de los medicamentos antimaláricos y la identificación de los tejidos donde ocurren su biotransformación y eliminación pueden ayudar a predecir si una determinada combinación de medicamentos metabolizados in vivo por una misma vía puede reducir la actividad antiparasitaria o tener efectos tóxicos en el paciente $(18,20)$. Vale la pena aclarar que estas interacciones pueden ocurrir tanto entre medicamentos antimaláricos como entre estos y otros fármacos administrados para tratar otras afecciones que estén presentes simultáneamente. Esto puede alterar la ruta de la biotransformación de un antimalárico y modificar la intensidad y la duración de la acción del compuesto.

Pocos estudios han analizado el efecto de la variación de la actividad enzimática del CYP2C8 sobre la respuesta a la AQ. Aunque se han descrito algunas variaciones farmacocinéticas y diversos efectos tóxicos durante el tratamiento con este medicamento (21), aún se desconoce la contribución del polimorfismo del gen CYP2C8 en este sentido. Recientemente se encontró que de 209 medicamentos estudiados, 48 inhibieron en $50 \%$ la conversión de la $A Q$ a su metabolito desetilamodiaquina y que el inhibidor más potente es el montelucast, un antagonista del receptor de leucotrienos (93). Es importante aclarar que la inhibición de la conversión de la $\mathrm{AQ}$ a desetilamodiaquina no conduce al fracaso terapéutico, ya que este medicamento es activo en su estado original, a pesar de que generalmente se le considera un profármaco por su rápida conversión y la mayor acción terapéutica de su metabolito.

Efectos del estado nutricional. Los cambios en el consumo de proteínas y su relación con la cantidad de carbohidratos y grasas presentes en la dieta, así como el insuficiente consumo de energía, pueden ocasionar variaciones en la respuesta terapéutica (94).

Macronutrientes. Las dietas ricas en proteínas aceleran las reacciones catalizadas por el complejo enzimático del
CYP-450 (95, 96), mientras que en niños con kwashiorkor - una forma grave de desnutrición proteínica- se altera el metabolismo de los medicamentos $(64,97)$. El consumo de carbohidratos influye en el metabolismo oxidativo de varios medicamentos y su deficiencia reduce la actividad del CYP-450 (96). Las dietas deficientes en ácidos grasos, independientemente de su grado de saturación, reducen el metabolismo de varios fármacos in vitro (94), mientras que el consumo de ácidos grasos estimula la actividad de las enzimas CYP3A y CYP2A1 $(98,99)$.

Micronutrientes. La deficiencia dietética de las vitaminas $\mathrm{A}, \mathrm{E}, \mathrm{C}$, niacina $\mathrm{y}$ riboflavina, así como de hierro, cinc y calcio, reduce la actividad del sistema enzimático del CYP-450 (cuadro 6). Estos micronutrientes provocan este efecto por tres vías: a) como factores de la transcripción de las enzimas del sistema de oxidación microsómica; b) como cofactores de las reacciones enzimáticas controladas por ese sistema; y c) como parte de la estructura terciaria de esas enzimas. La vitamina A modula la expresión de algunos genes hepáticos que se encargan de la transcripción de ciertas enzimas, como la CYP4A. En ratones alimentados con dietas deficientes en vitamina A se observó la reducción en la expresión de las enzimas CYP4A (64\%) y CYP3A (85\%) con respecto a los ratones que consumieron cantidades normales de esa vitamina (100) (cuadro 6). Se ha demostrado que la deficiencia de hierro y selenio en la dieta de ratones reduce la cantidad de citocromos en las células del intestino (105), aunque no se ha comprobado que la deficiencia de selenio provoque este tipo de cambio en el hígado. Esto puede indicar que las células intestinales requieren del selenio en la dieta para su actividad, mientras que las del hígado pueden suplir sus requerimientos de las reservas corporales de selenio $(105,106)$.

Desnutrición, deficiencia de micronutrientes y parasitosis intestinal en la población de zonas con malaria endémica. Se debe tener en cuenta que las

CUADRO 6. Efecto de la deficiencia de nutrientes sobre la actividad del citocromo P-450

\begin{tabular}{|c|c|c|}
\hline Nutriente & Efectos & Referencias \\
\hline Vitamina A & $\begin{array}{l}\text { Reducción del citocromo P-450 y oxidación de la aminopirina, } \\
\text { la etilmorfina, la anilina, el benzopireno y la 7-etoxicumarina }\end{array}$ & $(100,101,102)$ \\
\hline Niacina & Metabolismo de anestésicos & (96) \\
\hline Riboflavina & $\begin{array}{l}\text { Reducción de la NADPH-reductasa y oxidación de la } \\
\text { aminopirina, la etilmorfina, la anilina, el benzopireno y la } \\
\text { 7-etoxicumarina }\end{array}$ & $(96,103)$ \\
\hline Vitamina C & $\begin{array}{l}\text { Reducción del citocromo P-450, la NADPH-reductasa y de } \\
\text { varios procesos de monooxigenación }\end{array}$ & $(102)$ \\
\hline Vitamina $\mathrm{E}$ & Oxidación de la codeína, la etilmorfina y el benzopireno & $(102,104)$ \\
\hline Hierro & $\begin{array}{l}\text { Oxidación del hexobarbital y de la aminopirina, pero } \\
\text { incremento en la oxidación de la anilina }\end{array}$ & $(96,105,106)$ \\
\hline \multirow[t]{3}{*}{ Cinc } & $\begin{array}{l}\text { - Reducción del ARNm de la enzima CYP2C11 } \\
\text { - } 49 \% \text { y } 43 \% \text { de reducción del ARNm de la CYP3A2 y de la } \\
\text { CYP3A18, respectivamente } \\
\text { - } 253 \% \text { y } 238 \% \text { de incremento de la CYP2C12 y de la } \\
\text { CYP3A9, respectivamente } \\
\text { - } 67 \% \text { de reducción en la concentración de testosterona }\end{array}$ & $(107,108)$ \\
\hline & $\begin{array}{l}\text { Aumento de la concentración de la hormona luteinizante y de } \\
\text { la testosterona }\end{array}$ & \\
\hline & Alteración del metabolismo de esteroides endógenos & \\
\hline Calcio & Activación de varios procesos de monooxigenación & (96) \\
\hline
\end{tabular}


personas que habitan en las regiones con malaria endémica padecen con frecuencia de otras infecciones y enfermedades causadas por parásitos intestinales, protozoos y helmintos, así como de desnutrición proteínico-calórica y de una deficiencia de varios micronutrientes. La malaria y la infección simultánea con parásitos intestinales son frecuentes en personas con desnutrición (109) y afectan a la función hepática. En particular, la malaria crea un estado inflamatorio agudo del hígado que se ve agravado por las alteraciones que produce la desnutrición, especialmente cuando es crónica. La infección, la inflamación -incluso la provocada por la propia malaria - y los medicamentos antipalúdicos reducen la actividad del CYP-450 en el hígado. Parece lógico pensar que todas estas afecciones se reflejan en el metabolismo de los medicamentos en general y de los antimaláricos en particular (110).

Resulta claro, en consecuencia, que la dieta y el estado nutricional pueden modificar la farmacocinética o el metabolismo de los medicamentos debido a los cambios que provocan en la actividad del CYP-450. Por su parte, el estado nutricional y de salud, las restricciones dietéticas y las posibilidades de corregir la desnutrición con suplementos deben tomarse en cuenta al analizar el comportamiento de un medicamento y evaluar su acción terapéutica.

\section{DISCUSIÓN}

Según la información analizada, el tratamiento antimalárico puede ser ineficaz debido a la influencia de diversos factores:

- Factores del hospedero: demora en acudir al médico, administración de dosis subóptimas del fármaco (ya sea por la cantidad de medicamento o por el tiempo de tratamiento), deficiencias de la absorción o de la unión del principio activo a las proteínas plasmáticas, conversión insuficiente a la forma activa, excreción exce-siva del compuesto y alteraciones metabólicas

- Factores del medicamento: baja calidad del fármaco, propiedades físicoquímicas y su interacción con otros medicamentos

- Factores del parásito: especie, metabolismo, resistencia al medicamento y mutaciones genéticas

- Factores de las relaciones hospederomedicamento-parásito: interacciones entre el fármaco y los alimentos, grado de inmunidad antimalárica del paciente y su estado de salud general y nutricional.

El polimorfismo genético del CYP450 y diversos factores biológicos y sociales - como la dieta, la presencia de otras enfermedades, el uso de medicamentos y sus interacciones, entre otros - contribuyen a la gran variabilidad que se observa en el metabolismo de los medicamentos, incluso en un mismo paciente. Sin embargo, solo en los últimos años se han investigado las bases genéticas de los citocromos y se han dilucidado los mecanismos de acción de algunos fármacos y su metabolismo, lo que ha permitido caracterizar el proceso de biotransformación de la $A Q$ y la CQ. Se espera que nuevas investigaciones permitan responder a las interrogantes que quedan, entre ellas la ruta metabólica de otros medicamentos antimaláricos, la distribución en la población de los alelos de las enzimas que participan en su metabolismo, la contribución de tales mutaciones al fracaso terapéutico y la posibilidad de predecir la respuesta a los tratamientos antimaláricos.

La mayoría de los estudios que relacionan la respuesta terapéutica antimalárica con los factores que afectan a la actividad del CYP-450 se han realizado in vitro y en condiciones extremas de deficiencia nutricional, lo que se aleja de la realidad cotidiana de las personas. Además, si bien en la vida real existen factores adversos, también existen mecanismos fisiológicos que compensan esas deficiencias. Esto dificulta el análisis de la relación entre los factores biológicos y sociales y la respuesta in vivo a un medicamento.

Al estudiar la actividad del CYP-450 y la respuesta terapéutica antimalárica es necesario tomar muy en cuenta las particularidades de la farmacocinética del medicamento empleado. En particular, es importante tomar en consideración si el medicamento administrado tiene actividad antimalárica por sí mismo o si debe transformarse en un metabolito activo. En el primer caso, se hace muy difícil establecer una relación entre el CYP-450 y la respuesta terapéutica antimalárica.

El presente estudio tiene algunas limitaciones. En primer lugar, si bien las bases bibliográficas consultadas contienen la información más actual e importante sobre el tema analizado, no toma en cuenta la información publicada antes de 1980, que debe ser obtenida directamente de bibliotecas o archivos personales. En segundo lugar, a pesar de que se analizaron los artículos publicados en tres de los idiomas de mayor uso en la ciencia (español, inglés y portugués), no se tomó en cuenta la información publicada en otros idiomas.

La respuesta terapéutica a los medicamentos antimaláricos es un proceso multifactorial y poco comprendido. Por lo tanto, no es posible atribuirle a un fenotipo o genotipo particular del sistema enzimático del CYP-450 un papel determinado en la respuesta terapéutica antimalárica. Los factores biológicos y sociales — como la dieta y el estado nutricional- y los procesos inflamatorios e infecciosos que afectan con frecuencia a los pacientes que residen en las zonas con malaria endémica son elementos clave que pueden ayudar a comprender mejor la respuesta terapéutica a los diferentes medicamentos. 


\section{REFERENCIAS}

1. Organización Panamericana de la Salud. Evaluación de la eficacia terapéutica de los medicamentos para el tratamiento del paludismo por Plasmodium falciparum sin complicaciones en las Américas. Washington, D.C.: OPS; 1998. (OPS/HCP/HCT/113/98).

2. World Health Organization, Roll Back Malaria. The use of antimalarial drugs. Report of a WHO informal consultation. Geneva: WHO; 2001. (WHO/CDS/RBM/2001.33).

3. Blair S, Lacharme L, Carmona J, Tobon A. Resistencia de Plasmodium falciparum a los antimaláricos en Urabá y Bajo Cauca Antioqueño, 1998. Rev Epid Antioq. 1999;24:3-4.

4. Blair S, Lacharme LL, Fonseca JC, Tobon A. Resistencia de Plasmodium falciparum a tres antimaláricos en Turbo (Antioquia, Colombia), 1998. Rev Panam Salud Publica. 2001; 9(1):23-9.

5. Bloland PB. Drug resistance in malaria. Chamblee, Georgia: World Health Organization; 2001. (WHO/CDS/CSR/DRS/2001.4).

6. Ter Kuile FO, Luxemburger C, Nosten F, Thwai KL, Chongsuphajaisiddhi T, White NJ. Predictors of mefloquine treatment failure: a prospective study of 1590 patients with uncomplicated falciparum malaria. Trans $\mathrm{R}$ Soc Trop Med Hyg. 1995;89(6):660-4.

7. Hess FI, Iannuzzi A, Leafasia J, Cowdrey D, Nothdurft HD, von Sonnenburg F, et al. Risk factors of chloroquine resistance in Plasmodium falciparum malaria. Acta Trop. 1996; 61(4):293-306

8. Fontanet AL, Walker AM. Predictors of treatment failure in multiple drug-resistant falciparum malaria: results from a 42-day followup of 224 patients in eastern Thailand. Am J Trop Med Hyg. 1993;49(4):465-72.

9. Olanrewaju WI, Johnson AW. Chloroquineresistant Plasmodium falciparum malaria in Ilorin, Nigeria: prevalence and risk factors for treatment failure. Afr J Med Med Sci. 2001; 30(3):165-9.

10. Sowunmi A, Fateye BA, Happi TC, Gbotosho GO, Oduola AM. Plasmodium falciparum gametocytaemia in Nigerian children: Peripheral immature gametocytaemia as an indicator of a poor response to chloroquine treatment, and its relationship to molecular determinants of chloroquine resistance. Ann Trop Med Parasitol. 2003;97(5):453-68.

11. Arango E, Álvarez T, Carmona J, Blair S. Gametocitemia de Plasmodium falciparum según la respuesta terapéutica a sulfadoxinapirimetamina y cloroquina en dos municipios de Antioquia, Colombia. Biomedica. 2004; 24(1):79-88.

12. Blair S, Carmona J, Correa A. Malaria en niños: relación entre nutrición e inmunidad. Rev Panam Salud Publica. 2002;11(1):5-14.

13. Hillier K. Drug interaction with oral contraceptives. Fertil Contracept. 1978;2(1):5-8.

14. Lamba JK, Lin YS, Schuetz EG, Thummel KE. Genetic contribution to variable human CYP3A-mediated metabolism. Adv Drug Deliv Rev. 2002;54(10):1271-94.

15. Werck-Reichhart D, Feyereisen R. Cytochromes P-450: a success story. Genome Biol. 2000;1(6):3003.1-9.
16. Benet L, Kroetz D, Sheiner L. Dinámica de la absorción, distribución y eliminación de los fármacos. En: Hardman JG, Limbird LE, Gilman AG, eds. Las bases farmacológicas de la terapéutica de Goodman y Gilman. México, D.F.: McGraw-Hill Interamericana; 2003. Pp. 3-19.

17. Giao PT, de Vries PJ. Pharmacokinetic interactions of antimalarial agents. Clin Pharmacokinet. 2001:40(5):343-73.

18. Li XQ, Bjorkman A, Andersson TB, Gustafsson LL, Masimirembwa CM. Identification of human cytochrome $\mathrm{P}(450)$ s that metabolise anti-parasitic drugs and predictions of in vivo drug hepatic clearance from in vitro data. Eur J Clin Pharmacol. 2003;59(5-6):429-42.

19. Walker O, Birkett DJ, Alvan G, Gustafsson LL, Sjoqvist $\mathrm{F}$. Characterization of chloroquine plasma protein binding in man. Br J Clin Pharmacol. 1983;15(3):375-7.

20. Projean D, Baune B, Farinotti R, Flinois JP, Beaune $\mathrm{P}$, Taburet AM, et al. In vitro metabolism of chloroquine: identification of $\mathrm{CYP} 2 \mathrm{C} 8$, CYP3A4, and CYP2D6 as the main isoforms catalyzing N-desethylchloroquine formation. Drug Metab Dispos. 2003;31(6):748-54

21. Li XQ, Bjorkman A, Andersson TB, Ridderstrom M, Masimirembwa CM. Amodiaquine clearance and its metabolism to $\mathrm{N}$-desethylamodiaquine is mediated by CYP2C8: a new high affinity and turnover enzyme-specific probe substrate. J Pharmacol Exp Ther. 2002; 300(2):399-407.

22. Krishna S, White NJ. Pharmacokinetics of quinine, chloroquine and amodiaquine. Clinical implications. Clin Pharmacokinet. 1996;30(4) 263-99.

23. Karbwang J, Na-Bangchang K. Clinical application of mefloquine pharmacokinetics in the treatment of $P$. falciparum malaria. Fundam Clin Pharmacol. 1994;8(6):491-502.

24. Lu AH, Shu Y, Huang SL, Wang W, Ou-Yang DS, Zhou $\mathrm{HH}$. In vitro proguanil activation to cycloguanil is mediated by CYP2C19 and CYP3A4 in adult Chinese liver microsomes. Acta Pharmacol Sin. 2000;21(8):747-52.

25. Edstein MD, Veenendaal JR, Scott HV, Rieckmann KH. Steady-state kinetics of proguanil and its active metabolite, cycloguanil, in man. Chemotherapy. 1988;34(5):385-92.

26. República de Colombia, Ministerio de Salud Dirección General de Promoción y Prevención. Guía de atención clínica para el diagnóstico y tratamiento de la malaria. Santa Fe de Bogotá: Ministerio de Salud de Colombia; 1999.

27. Walker O, Dawodu AH, Salako LA, Alvan G, Johnson AO. Single dose disposition of chloroquine in kwashiorkor and normal children: evidence for decreased absorption in kwashiorkor. Br J Clin Pharmacol. 1987;23(4) 467-72.

28. Tulpule A, Krishnaswamy K. Chloroquine kinetics in the undernourished. Eur J Clin Pharmacol. 1983;24(2):273-6.

29. Fontaine F, de Sousa G, Burcham PC, Duchene P, Rahmani R. Role of cytochrome P-450 $3 \mathrm{~A}$ in the metabolism of mefloquine in human and animal hepatocytes. Life Sci. 2000;66(22): 2193-212.
30. Kaneko A, Kaneko O, Taleo G, Bjorkman A, Kobayakawa T. High frequencies of CYP2C19 mutations and poor metabolism of proguanil in Vanuatu. Lancet. 1997;349(9056):921-2.

31. Hamedi $Y$, Nateghpour M, Tan-ariya P, Tiensuwan M, Silachamroon U, Looareesuwan $S$. Plasmodium vivax malaria in Southeast Iran in 1999-2001: establishing the response to chloroquine in vitro and in vivo. Southeast Asian J Trop Med Public Health. 2002;33(3): 512-8.

32. Cutler DJ. Possible mechanisms of action of antimalarials in rheumatic disease. Agents Actions Suppl. 1993;44:139-43.

33. Basco LK, Same-Ekobo A, Ngane VF, Ndounga M, Metoh T, Ringwald P, et al. Therapeutic efficacy of sulfadoxine-pyrimethamine, amodiaquine and the sulfadoxine-pyrimethamineamodiaquine combination against uncomplicated Plasmodium falciparum malaria in young children in Cameroon. Bull World Health Organ. 2002; 80(7):538-45.

34. López YL, Salazar A. Evaluación de la resistencia in vivo a los medicamentos antimaláricos. El Bagre, Antioquia, 1998. Rev Epidem Antioquia. 1999;24(3-4):181-94.

35. Wernsdorfer WH. Epidemiology of drug resistance in malaria. Acta Trop. 1994;56(2-3): $143-56$.

36. Schwartz E, Potasman I, Rotenberg M, Almog $\mathrm{S}$, Sadetzki S. Serious adverse events of mefloquine in relation to blood level and gender. Am J Trop Med Hyg. 2001;65(3):189-92.

37. Barrett PJ, Emmins PD, Clarke PD, Bradley DJ. Comparison of adverse events associated with use of mefloquine and combination of chloroquine and proguanil as antimalarial prophylaxis: postal and telephone survey of travellers. Br Med J. 1996;313(7056):525-8.

38. Radloff PD, Philipps J, Nkeyi M, Hutchinson D, Kremsner PG. Atovaquone and proguanil for Plasmodium falciparum malaria. Lancet. 1996;347(9014):1511-4.

39. McChesney EW, Fasco MJ, Banks WF, Jr. The metabolism of chloroquine in man during and after repeated oral dosage. J Pharmacol Exp Ther. 1967;158(2):323-31.

40. Gustafsson LL, Lindstrom B, Grahnen A Alvan G. Chloroquine excretion following malaria prophylaxis. Br J Clin Pharmacol. 1987;24(2):221-4.

41. Salako LA, Walker O, Iyun AO. Pharmacokinetics of chloroquine in renal insufficiency. Afr J Med Med Sci. 1984;13(3-4):177-82.

42. Walker O, Salako LA, Alvan G, Ericsson O, Sjoqvist $\mathrm{F}$. The disposition of chloroquine in healthy Nigerians after single intravenous and oral doses. Br J Clin Pharmacol. 1987 23(3):295-301.

43. Salako LA, Aderounmu AF, Walker O. Influence of route of administration on the pharmaco-kinetics of chloroquine and desethylchloroquine. Bull World Health Organ. 1987;65(1):47-50.

44. Tett SE, Cutler DJ, Day RO, Brown KF. Bioavailability of hydroxychloroquine tablets in healthy volunteers. Br J Clin Pharmacol. 1989;27(6):771-9.

45. Na-Bangchang K, Limpaibul L, Thanavibul A, Tan-ariya P, Karbwang J. The pharmacokinet- 
ics of chloroquine in healthy Thai subjects and patients with Plasmodium vivax malaria. $\mathrm{Br} \mathrm{J}$ Clin Pharmacol. 1994;38(3):278-81.

46. Winstanley P, Edwards G, Orme M, Breckenridge $\mathrm{A}$. The disposition of amodiaquine in man after oral administration. Br J Clin Pharmacol. 1987;23(1):1-7.

47. Na-Bangchang K, Molunto P, Banmairuroi V, Thanavibul A, Karbwang J. Pharmacokinetics of mefloquine when given as a single and two divided-dose regimens. Int J Clin Pharmacol Res. 1995;15(5-6):215-20.

48. Jamaludin A, Mohamad M, Navaratnam V, Yeoh PY, Wernsdorfer WH. Multiple-dose pharmacokinetic study of proguanil and cycloguanil following 12-hourly administration of $100 \mathrm{mg}$ proguanil hydrochloride. Trop Med Parasitol. 1990;41(3):268-72.

49. White NJ, Watt G, Bergqvist $Y$, Njelesani EK. Parenteral chloroquine for treating falciparum malaria. J Infect Dis. 1987;155(2): 192-201

50. Winstanley PA, Simooya O, Kofi-Ekue JM, Walker O, Salako LA, Edwards G, et al. The disposition of amodiaquine in Zambians and Nigerians with malaria. Br J Clin Pharmacol. 1990;29(6):695-701.

51. Simpson JA, Price R, ter Kuile F, TejaIsavatharm P, Nosten F, Chongsuphajaisiddhi $\mathrm{T}$, et al. Population pharmacokinetics of mefloquine in patients with acute falciparum malaria. Clin Pharmacol Ther. 1999;66(5): 472-84.

52. Basco LK, Tahar R, Ringwald P. Molecular basis of in vivo resistance to sulfadoxinepyrimethamine in African adult patients infected with Plasmodium falciparum malaria parasites. Antimicrob Agents Chemother. 1998;42(7):1811-4.

53. Kaneko A, Bergqvist $Y$, Takechi M, Kalkoa M, Kaneko O, Kobayakawa T, et al. Intrinsic efficacy of proguanil against falciparum and vivax malaria independent of the metabolite cycloguanil. J Infect Dis. 1999;179(4):974-9.

54. Cavaco I, Stromberg-Norklit J, Kaneko A, Msellem MI, Dahoma M, Ribeiro VL, et al. CYP2C8 polymorphism frequencies among malaria patients in Zanzibar. Eur J Clin Pharmacol. 2005;61:15-8

55. Guengerich FP, Parikh A, Yun $\mathrm{CH}$, Kim D, Nakamura K, Notley LM, et al. What makes P450s work? Searches for answers with known and new P450s. Drug Metab Rev. 2000;32(3-4): 267-81.

56. Murray M. Induction and inhibition of CYPs and implications for medicine. Mol Aspects Med. 1999;20(1-2):24-137.

57. Meyer UA. Pharmacogenetics and adverse drug reactions. Lancet. 2000;356(9242):1667-71.

58. Ingelman-Sundberg M, Daly AK, Nebert DW. Nomenclature files for human cytochrome P-450 alleles. [Sitio en internet] Page of the Human Cytochrome P-450 (CYP) Allele Nomenclature Committee. Hallado en: http:// www.imm.ki.se/CYPalleles/. Acceso el 31 de agosto de 2005.

59. Wormhoudt LW, Commandeur JN, Vermeulen NP. Genetic polymorphisms of human N-acetyltransferase, cytochrome P-450, glutathione-S-transferase, and epoxide hydrolase enzymes: relevance to xenobiotic metabo- lism and toxicity. Crit Rev Toxicol. 1999;29(1): 59-124.

60. Dai D, Zeldin DC, Blaisdell JA, Chanas B, Coulter SJ, Ghanayem BI, et al. Polymorphisms in human CYP2C8 decrease metabolism of the anticancer drug paclitaxel and arachidonic acid. Pharmacogenetics. 2001; 11(7):597-607.

61. García-Martín E, Martínez C, Ladero JM, Gamito FJ, Agúndez JA. High frequency of mutations related to impaired CYP2C9 metabolism in a Caucasian population. Eur J Clin Pharmacol. 2001;57(1):47-9.

62. Kaneko A, Taleo G, Kalkoa M, Yamar S, Kobayakawa T, Bjorkman A. Malaria eradication on islands. Lancet. 2000;356(9241):1560-4.

63. Branch RA, Adedoyin A, Frye RF, Wilson JW, Romkes M. In vivo modulation of CYP enzymes by quinidine and rifampin. Clin Pharmacol Ther. 2000;68(4):401-11.

64. Morgan ET. Regulation of cytochrome p450 by inflammatory mediators: why and how? Drug Metab Dispos. 2001;29(3):207-12.

65. Cheng PY, Morgan ET. Hepatic cytochrome P-450 regulation in disease states. Curr Drug Metab. 2001;2(2):165-83.

66. Uhl K, Grace JM, Kocisko DA, Jennings BT, Mitchell AL, Brewer TG. Effects of Plasmodium berghei infection on cytochromes P-450 2E1 and 3A2. Eur J Drug Metab Pharmacokinet. 1999;24(2):169-76.

67. Srivastava P, Pandey VC. Studies on hepatic mitochondrial cytochrome P-450 during Plasmodium yoelii infection and pyrimethamine treatment in mice. Ecotoxicol Environ Saf. 2000;46(1):19-22.

68. Srivastava P, Sharma SN, Shukla OP, Pandey VC. Studies of the hepatic mitochondrial and microsomal mixed-function oxidase system during Plasmodium yoelii infection and inducer treatment in Swiss albino mice. Trop Med Int Health. 1997;2(10):989-92.

69. Srivastava P, Pandey VC. Heme oxygenase and related indices in chloroquine-resistant and -sensitive strains of Plasmodium berghei. Int J Parasitol. 1995;25(9):1061-4.

70. Srivastava P, Puri SK, Dutta GP, Pandey VC. Effect of chloroquine on hepatic hemeoxygenase during Plasmodium berghei infection in mice. Int J Parasitol. 1993;23(2):231-4.

71. Srivastava P, Tripathi LM, Puri SK, Dutta GP, Pandey VC. Effect of Plasmodium berghei infection and chloroquine on the hepatic drug metabolizing system of mice. Int J Parasitol. 1991;21(4):463-6.

72. Ismail S, Kokwaro GO, Back DJ, Edwards G. Effect of malaria infection on the pharmacokinetics of paracetamol in rat. Xenobiotica. 1994; 24(6):527-33.

73. Glazier AP, Kokwaro GO, Ismail S, Edwards G. Effect of an experimental malaria infection on the metabolism of phenacetin in the rat isolated perfused liver. Xenobiotica. 1994;24(8): 785-93.

74. Kokwaro GO, Szwandt IS, Glazier AP, Ward SA, Edwards G. Metabolism of caffeine and theophylline in rats with malaria and endotoxin-induced fever. Xenobiotica. 1993; 23(12):1391-7.

75. Kokwaro GO, Ismail S, Glazier AP, Ward SA Edwards G. Effect of malaria infection and endotoxin-induced fever on the metabolism of antipyrine and metronidazole in the rat. Biochem Pharmacol. 1993;45(6):1243-9.

76. Mansor SM, Edwards G, Roberts PJ, Ward SA The effect of malaria infection on paracetamol disposition in the rat. Biochem Pharmacol. 1991;41(11):1707-11.

77. Mansor SM, Ward SA, Edwards G. The effect of malaria infection on antipyrine metabolite formation in the rat. Biochem Pharmacol. 1991;41(8):1264-6.

78. Mansor SM, Ward SA, Edwards G, Hoaksey $\mathrm{PE}$, Breckenridge AM. The effect of malaria infection on the disposition of quinine and quinidine in the rat isolated perfused liver preparation. J Pharm Pharmacol. 1990;42(6): 428-32.

79. Mihaly GW, Date NM, Ireton HJ, Smallwood RA. The effect of malaria infection on primaquine elimination in the isolated perfused rat liver. Biochem Pharmacol. 1987;36(2): 225-8.

80. Saxena N, Saxena A, Dutta GP, Ghatak S, Pandey VC. Effect of Plasmodium yoelii nigeriensis infection and chloroquine on the hepatic mixed function oxidase system of mice. Mol Biochem Parasitol. 1987;24(3):283-7.

81. Álvares AP, Ueng TH, Scheibel LW, Hollingdale MR. Impairment of hepatic cytochrome P-450-dependent monooxygenases by the malaria parasite Plasmodium berghei. Mol Biochem Parasitol. 1984;13(3):277-82.

82. McKindley DS, Boulet J, Sachdeva K, Wang P, Chichester C. Endotoxic shock alters the pharmacokinetics of lidocaine and monoethylglycinexylidide. Shock. 2002;17(3):199-204.

83. McKindley DS, Chichester C, Raymond R. Effect of endotoxin shock on the clearance of lidocaine and indocyanine green in the perfused rat liver. Shock. 1999;12(6):468-72.

84. Mihaly GW, Date NM, Veenendaal JR, Newman KT, Smallwood RA. Decreased hepatic elimination of pyrimethamine during malaria infection. Studies in the isolated perfused rat liver. Biochem Pharmacol. 1987;36(17):2827-9.

85. Funseth E, Pahlman M, Eloranta ML, Friman G, Ilback NG. Effects of coxsackievirus B3 infection on the acute-phase protein metallothionein and on cytochrome P-4501A1 involved in the detoxification processes of TCDD in the mouse. Sci Total Environ. 2002;284(1-3):37-47.

86. McCarthy JS, Furner RL, Van Dyke K, Stitzel RE. Effects of malarial infection on host microsomal drug-metabolizing enzymes. Biochem Pharmacol. 1970;19(4):1341-9.

87. Srivastava P, Puri SK, Pandey VC. Effect of Plasmodium berghei infection and antimalarial treatment on heme synthesis in mice. Int J Parasitol. 1994;24(5):677-9.

88. Hirano Y, Mizutani T. Study of inhibition of CYP2A6 by some drugs derived from quinoline. J Pharm Pharmacol. 2003;55(12):1667-72.

89. Simooya OO, Sijumbil G, Lennard MS, Tucker GT. Halofantrine and chloroquine inhibit CYP2D6 activity in healthy Zambians. Br J Clin Pharmacol. 1998;45(3):315-7.

90. Ndifor AM, Howells RE, Bray PG, Ngu JL, Ward SA. Enhancement of drug susceptibility in Plasmodium falciparum in vitro and Plasmodium berghei in vivo by mixed-function oxidase inhibitors. Antimicrob Agents Chemother. 1993;37(6):1318-23. 
91. Ndifor AM, Ward SA, Howells RE. Cytochrome P-450 activity in malarial parasites and its possible relationship to chloroquine resistance. Mol Biochem Parasitol. 1990;41(2): 251-7.

92. Surolia N, Karthikeyan G, Padmanaban G. Involvement of cytochrome P-450 in conferring chloroquine resistance to the malarial parasite Plasmodium falciparum. Biochem Biophys Res Commun. 1993;197(2):562-9.

93. Walsky RL, Gaman EA, Obach RS. Examination of 209 drugs for inhibition of cytochrome P-450 2C8. J Clin Pharmacol. 2005;45(1):68-78.

94. Walter-Sack I, Klotz U. Influence of diet and nutritional status on drug metabolism. Clin Pharmacokinet. 1996;31(1):47-64.

95. Anderson KE, Conney AH, Kappas A. Nutritional influences on chemical biotransformations in humans. Nutr Rev. 1982;40(6):161-71.

96. Guengerich FP. Influence of nutrients and other dietary materials on cytochrome P-450 enzymes. Am J Clin Nutr. 1995;61(Suppl3): 651S-8S.

97. Campbell TC, Hayes JR. The effect of quantity and quality of dietary protein on drug metabolism. Fed Proc. 1976;35(13):2470-4.

98. Yoo JS, Hong JY, Ning SM, Yang CS. Roles of dietary corn oil in the regulation of cytochromes P-450 and glutathione S-transferases in rat liver. J Nutr. 1990;120(12):1718-26.
99. Yoo JS, Ning SM, Pantuck CB, Pantuck EJ, Yang CS. Regulation of hepatic microsomal cytochrome P450IIE1 level by dietary lipids and carbohydrates in rats. J Nutr. 1991;121(7): 959-65.

100. Murray M, Sefton RM, Croft KD, Butler AM. Differential regulation of endobiotic-oxidizing cytochromes P-450 in vitamin A-deficient male rat liver. Br J Pharmacol. 2001;134(7): 1487-97.

101. Yang CS, Yoo JS. Dietary effects on drug metabolism by the mixed-function oxidase system. Pharmacol Ther. 1988;38(1):53-72.

102. Bidlack WR, Brown RC, Mohan C. Nutritional parameters that alter hepatic drug metabolism, conjugation, and toxicity. Fed Proc. 1986;45(2):142-8

103. Yang CS. Alterations of the aryl hydrocarbon hydroxylase system during riboflavin depletion and repletion. Arch Biochem Biophys. 1974;160(2):623-30.

104. Traber MG. Vitamin E, nuclear receptors and xenobiotic metabolism. Arch Biochem Biophys. 2004;423(1):6-11.

105. Pascoe GA, Sakai-Wong J, Soliven E, Correia MA. Regulation of intestinal cytochrome P-450 and heme by dietary nutrients. Critical role of selenium. Biochem Pharmacol. 1983; 32(20):3027-35.

106. Pascoe GA, Correia MA. Structural and functional assembly of rat intestinal cytochrome
P-450 isozymes. Effects of dietary iron and selenium. Biochem Pharmacol. 1985;34(5): 599-608.

107. Xu Z, Kawai M, Bandiera SM, Chang TK. Influence of dietary zinc deficiency during development on hepatic CYP2C11, CYP2C12, CYP3A2, CYP3A9, and CYP3A18 expression in postpubertal male rats. Biochem Pharmacol. 2001;62(9):1283-91.

108. Om AS, Chung KW. Dietary zinc deficiency alters 5-alpha-reduction and aromatization of testosterone and androgen and estrogen receptors in rat liver. J Nutr. 1996;126(4): 842-8.

109. Koski KG, Scott ME. Gastrointestinal nematodes, nutrition and immunity: breaking the negative spiral. Annu Rev Nutr. 2001;21: 297-321.

110. Blair S, Álvarez G, Villa Andrés, Carmona J, Osorio R. Estado nutricional y niveles de inmunoglobulinas y citocinas en niños con malaria. An Pediatr. 2003;58(5):418-24.

Manuscrito recibido el 18 de marzo de 2005. Aceptado para publicación, tras revisión, el 2 de agosto de 2005.
ABSTRACT

Cytochrome P-450 and the response to antimalarial drugs
Objectives. To assess the relationship between the genetic and phenotypic factors linked to the cytochrome P-450 enzyme system and the response to the antimalarial drugs chloroquine, amodiaquine, mefloquine, and proguanil, as well as to determine how certain biological and social factors of the host influence the behavior of this enzymatic complex.

Methods. We performed a systematic review of the medical bibliographic databases PubMed, Excerpta Medica, LILACS, and SciELO by using the following Spanish and English descriptors: "CYP-450" and "citocromo P-450" in combination with "proguanil" (and with "mefloquina," "cloroquina," and "amodiaquina"), "farmacocinética de proguanil" (and the same using "mefloquina," "cloroquina," and "amodiaquina"), "resistencia a proguanil" (and the same using "mefloquina," "cloroquina," and "amodiaquina"), "metabolismo," "farmacogenética," "enfermedad," "inflamación," "infección," "enfermedad hepática," "malaria," "nutrición," and "desnutrición." The same terms were used in English. The search included only articles published in Spanish, English, and Portuguese on or before 30 June 2005 that dealt with only four antimalarial drugs: amodiaquine, chloroquine, mefloquine, and proguanil.

Results. Some genetic factors linked to human cytochrome P-450 (mainly its polymorphism), as well as other biological and social factors (the presence of disease itself, or of inflammation and infection, the use of antimalarials in their various combinations, and the patient's nutritional status) influence the behavior of this complex enzymatic system. It has only been in the last decade that the genetics of the cytochromes has been explored and that the mechanisms underlying some therapeutic interactions and aspects of drug metabolism have been uncovered, making it possible to characterize the biotransformation pathway of amodiaquine and chloroquine. Hopefully new research will help answer the questions that still remain, some of which pertain to the metabolism of other antimalarial drugs, the distribution in the population of the genetic alleles linked to the enzymes involved in their metabolism, the contribution of these genetic mutations to therapeutic failure, and the possibility of predicting the response to antimalarial therapy.

Conclusions. The therapeutic response to antimalarial drugs is a multifactorial process that is poorly understood, so that it is not possible to ascribe to a specific phenotype or genotype a role in the response to antimalarial therapy. Attention should be given to biological and social factors, such as diet, nutritional status, and inflammatory and infectious processes that are often present in areas where malaria is endemic.

Key words Cytochrome P-450 enzyme system, Plasmodium falciparum, malaria, antimalarials. 